\title{
Formation and erosion of the seasonal thermocline in the Kuroshio Extension Recirculation Gyre
}

\author{
Meghan F. Cronin ${ }^{\mathrm{a}, *}$, Nicholas A. Bond ${ }^{\mathrm{b}}$, J. Thomas Farrar ${ }^{\mathrm{c}}$, Hiroshi Ichikawa ${ }^{\mathrm{d}}$, Steven R. Jayne ${ }^{\mathrm{c}}$, \\ Yoshimi Kawai ${ }^{\mathrm{d}}$, Masanori Konda ${ }^{\mathrm{d}, \mathrm{e}}$, Bo Qiu ${ }^{\mathrm{f}}$, Luc Rainville ${ }^{\mathrm{g}}$, Hiroyuki Tomita ${ }^{\mathrm{d}}$ \\ a NOAA Pacific Marine Environmental Laboratory, 7600 Sand Point Way NE, Seattle, WA 98115, USA \\ ${ }^{\mathrm{b}}$ University of Washington/NOAA Joint Institute for the Study of Atmosphere and Ocean, 7600 Sand Point Way NE, Seattle, WA 98115, USA \\ ${ }^{\mathrm{c}}$ Woods Hole Oceanographic Institution, 266 Woods Hole Road, Woods Hole, MA 02543, USA \\ ' Japan Agency for Marine and Earth Science Technology, Research Institute for Global Change, Yokosuka, Kanagawa 237-0061, Japan \\ e Kyoto University, Graduate School of Science, Kitashirakawa-Oiwake, Sakyo, Kyoto 606-8502, Japan \\ ${ }^{\mathrm{f}}$ University of Hawaii, School of Ocean and Earth Science and Technology, 1000 Pope Rd, Honolulu, HI 96822, USA \\ ${ }^{\mathrm{g}}$ University of Washington/Applied Physics Laboratory, 1013 NE 40th Street, Seattle, WA 98105, USA
}

\section{A R T I C L E I N F O}

Available online 21 July 2012

\section{Keywords}

Air-sea interaction

Heat budget

Kuroshio Extension

Mixing processes

\begin{abstract}
A B S T R A C T
Data from the Kuroshio Extension Observatory (KEO) surface mooring are used to analyze the balance of processes affecting the upper ocean heat content and surface mixed layer temperature variations in the Recirculation Gyre (RG) south of the Kuroshio Extension (KE). Cold and dry air blowing across the $\mathrm{KE}$ and its warm RG during winter cause very large heat fluxes out of the ocean that result in the erosion of the seasonal thermocline in the RG. Some of this heat is replenished through horizontal heat advection, which may enable the seasonal thermocline to begin restratifying while the net surface heat flux is still acting to cool the upper ocean. Once the surface heat flux begins warming the ocean, restratification occurs rapidly due to the low thermal inertia of the shallow mixed layer depth. Enhanced diffusive mixing below the mixed layer tends to transfer some of the mixed layer heat downward, eroding and potentially modifying sequestered subtropical mode water and even the deeper waters of the main thermocline during winter. Diffusivity at the base of the mixed layer, estimated from the residual of the mixed layer temperature balance, is roughly $3 \times 10^{-4} \mathrm{~m}^{2} / \mathrm{s}$ during the summer and up to two orders of magnitude larger during winter. The enhanced diffusivities appear to be due to large inertial shear generated by wind events associated with winter storms and summer tropical cyclones. The diffusivity's seasonality is likely due to seasonal variations in stratification just below the mixed layer depth, which is large during the summer when the seasonal thermocline is fully developed and low during the winter when the mixed layer extends to the top of the thermocline.
\end{abstract}

Published by Elsevier Ltd.

\section{Introduction}

Like all western boundary current extensions, the Kuroshio Extension (KE) jet is a region of intense air-sea interaction. During winter, when cold and dry air from the Asian landmass blows over the warm KE water, extremely large amounts of heat are released to the atmosphere by the ocean. This heating can warm and destabilize the atmospheric boundary layer, affecting the clouds (Tokinaga et al., 2009) and surface winds (Nonaka and Xie, 2003). Differential heating associated with the KE's Sea Surface Temperature (SST) front can cause surface wind convergence and a secondary circulation within the troposphere (Minobe et al., 2008; Tokinaga et al., 2009), as well as enhanced baroclinicity that can affect the storm track (Taguchi et al., 2009).

\footnotetext{
* Corresponding author. Tel.: +1 206526 6449; fax: +1 2065266744 .

E-mail address: Meghan.F.Cronin@noaa.gov (M.F. Cronin).
}

Turbulent air-sea heat fluxes act to reduce the air-sea temperature difference, and thereby damp temperature anomalies in the atmosphere and ocean. The actual response of the ocean to the heat flux, however, depends upon the depth to which the wellmixed surface temperature extends (i.e., the thermal inertia of the water), and oceanic processes that affect the upper water column's temperature structure and heat content. These oceanic processes can in turn affect the air-sea temperature differences and thus play an active role in determining the magnitude and variability of the air-sea heat fluxes. For example, if the heat lost by the ocean to the atmosphere is replenished through heat advection, the air-sea interactions can be sustained or even grow. Thus in this study we focus on processes affecting the heat content and mixed layer temperature using data from the Kuroshio Extension Observatory (KEO) surface mooring.

The KEO mooring is located just south of the eastward flowing $\mathrm{KE}$ jet, where the thermocline is deep and its bowl shape is associated with an anti-cyclonic Recirculation Gyre (RG). Above 
the permanent thermocline and beneath the seasonal thermocline lies a thick layer of uniform water, referred to as the North Pacific Subtropical Mode Water (STMW) (Hanawa and Talley, 2001; Oka and Qiu, 2012). When the seasonal thermocline is completely eroded during winter, the mode water is in contact with the atmosphere, i.e., is ventilated. It is generally believed that mode water is modified only when it is directly in contact with the atmosphere, while at other times it retains its properties. In this way, mode water can provide a memory of the previous winter that can reemerge during the subsequent ventilation period (Alexander and Deser, 1995).

The size of the RG and region of wintertime ventilation can have significant interannual-to-decadal variability associated with quasi-stable and unstable regime shifts in the KE system (Qiu, 2002). During the stable state, the KE jet is shifted to the north, has minimal eddy activity, and the RG is elongated. During the unstable state, the KE jet is highly convoluted with meander troughs that shift the mean axis of the jet southward and the contracted RG is sometimes indistinguishable from anticyclones associated with meander crests.

In this study we use data collected during and following the Kuroshio Extension System Study (KESS) experiment (Donohue et al., 2008). In particular, we use data from the KEO surface mooring and Argo floats in the RG south of the KE jet to determine the extent to which the seasonal thermocline is formed and eroded through seasonal variations in the air-sea heat fluxes. We also investigate the roles of oceanic processes such as heat advection, eddies, and turbulent mixing. Diffusive mixing receives special attention since it can contribute to the erosion of the seasonal thermocline, and ultimately the downward transport of heat to the STMW that would otherwise be trapped near the surface.

Our primary analysis tool will be the upper ocean heat budget. As discussed in the following section, through analysis of the heat budget for the upper $250 \mathrm{~m}$, we are able to diagnose the roles of surface heat fluxes, and horizontal and vertical heat advection. Likewise, through analysis of the upper ocean mixed layer temperature budget, we are able to diagnose how heat is distributed vertically and how it is transmitted downward through turbulent mixing. Data used in the analyses are described in Section 3. Results are described in Section 4 and summarized in Section 5. The error analysis is described in Appendix 1.

\section{Methodology}

As discussed in the previous section, the STMW lies between the base of the seasonal thermocline and the top of the permanent thermocline. We thus first evaluate the upper ocean heat budget integrated to a fixed level $(H)$ within the core of the STMW (i.e., $250 \mathrm{~m}$ ). To the degree that the water is vertically uniform at this level, we can assume that the heat flux due to vertical mixing is negligible there. Likewise, penetrative radiation is negligible at $250 \mathrm{~m}$, and for convenience we assume that the horizontal diffusion is negligible. With these assumptions and the assumption that the fluid is incompressible, integration of the temperature equation from the surface to $z=-H$ results in an upper ocean heat balance:

$$
\begin{aligned}
\frac{\partial}{\partial t} \int_{-H}^{0} \rho_{0} C_{p} T d z= & Q_{0}-w_{-H} \rho_{0} C_{p}\left(T_{a}-T_{-H}\right) \\
& +\left(-\boldsymbol{u}_{\boldsymbol{a}} \cdot \nabla \int_{-H}^{0} \rho_{0} C_{p} T d z-\nabla \cdot \int_{-H}^{0} \rho_{0} C_{p} \boldsymbol{u}^{\prime} T^{\prime} \partial z\right),
\end{aligned}
$$

where $\rho_{0} C_{p}$ is the volumetric heat capacity of seawater, taken to be $4.088 \times 10^{6} \mathrm{~J}^{\circ} \mathrm{C}^{-1} \mathrm{~m}^{-3}, T$ is the depth-dependent temperature,
$T_{a}$ and $\boldsymbol{u}_{\boldsymbol{a}}$ are the vertically averaged temperature and horizontal velocity within the $250 \mathrm{~m}$ layer, $T^{\prime}$ and $\boldsymbol{u}^{\prime}$ are the anomalies from the layer's vertical average, $T_{-H}$ and $w_{-H}$ are the temperature and vertical velocity at the base of the layer $H$, and $Q_{0}$ is the flux of heat through the air-sea interface. In other words, the local changes in the heat content over $250 \mathrm{~m}$ are due to heat fluxes through the surface, vertical advection through the base of the layer, and horizontal advection of heat.

Since we are interested in the intraseasonal and seasonal variations in the heat content, the budget is evaluated with daily averaged data and all terms are smoothed with a 61-day triangular filter. In this part of the study we will address processes affecting the surface heat fluxes (e.g., the disequilibrium between the air mass and the water below it), vertical advection, and the horizontal heat advection (third term on rhs of Eq. (1)). We will also investigate the role of advection by eddies by comparing the heat content as measured by the KEO surface mooring to the ambient heat content measured by Argo floats in the RG but not in cold-core eddies.

To investigate the vertical distribution of heat and the role of mixing, we again evaluate the heat budget, but this time over a relatively well-mixed surface layer, $h$. To the degree that this layer is uniform in temperature, the vertically averaged temperature will be equivalent to the surface temperature and the layer temperature budget can be used to identify processes controlling SST variability. For convenience, we assume that the stratified shear flow convergence is negligible, and, as with Eq. (1), that the horizontal diffusion is negligible. Thus the surface mixed layer temperature budget can be expressed as:

$\frac{\partial}{\partial t} T_{a}=\frac{Q_{0}-\left.Q_{p e n}\right|_{z=-h}}{\rho C_{p} h}-u_{a} \cdot \nabla T_{a}-\left(w_{-h}+\frac{d h}{d t}\right) \frac{\left(T_{a}-T_{-h}\right)}{h}-\left.\frac{\kappa}{h} \frac{\partial T}{\partial z}\right|_{z=-h}$

where $T_{a}$ and $u_{a}$ are in this case the vertically averaged temperature and horizontal velocity within the mixed layer, $Q_{p e n}$ is the radiative heat flux penetrating through the base of the mixed layer, and $\kappa$ is the vertical diffusivity coefficient. Eq. (2) states that the local rate of change in the vertically averaged mixed layer temperature (a proxy for SST) is caused by surface heat fluxes absorbed in the mixed layer, horizontal advection by the vertically averaged currents, vertical entrainment into the mixed layer, and vertical diffusion. Since these processes will occur on synoptic timescales, the mixed layer temperature budget is evaluated with daily-averaged data and all terms are smoothed with a 5-day triangular filter. In this part of the study, the vertical distribution of heat (the depth of the well-mixed surface layer), diffusive mixing, and diffusivity at the base of the mixed layer are target variables to be diagnosed. In order to investigate processes that may account for enhanced diffusivity, hourly data are used to evaluate the buoyancy frequency $(N)$, shear $\left(S\right.$, where $S^{2}$ is $(\partial u / \partial z)^{2}$ $\left.+(\partial v / \partial z)^{2}\right)$, and the Richardson number ratio $\left(R i=N^{2} / S^{2}\right)$ in the $20 \mathrm{~m}$ layer below the base of the mixed layer. Richardson number values near or below a critical level $(\sim 0.25)$ favor shear-instability mixing.

\section{Data}

The primary data used in this study are from the KEO surface mooring that was first deployed in mid-June 2004 during KESS and which then continued as an ongoing OceanSITES time series reference station (Cronin et al., 2008). Our study period extends from June 2004 to September 2009 and includes both the quasistable and unstable regimes of the KE system (Fig. 1). Thus for making comparisons between the different KE regimes, we will compute statistics over two 1-year periods when data were 

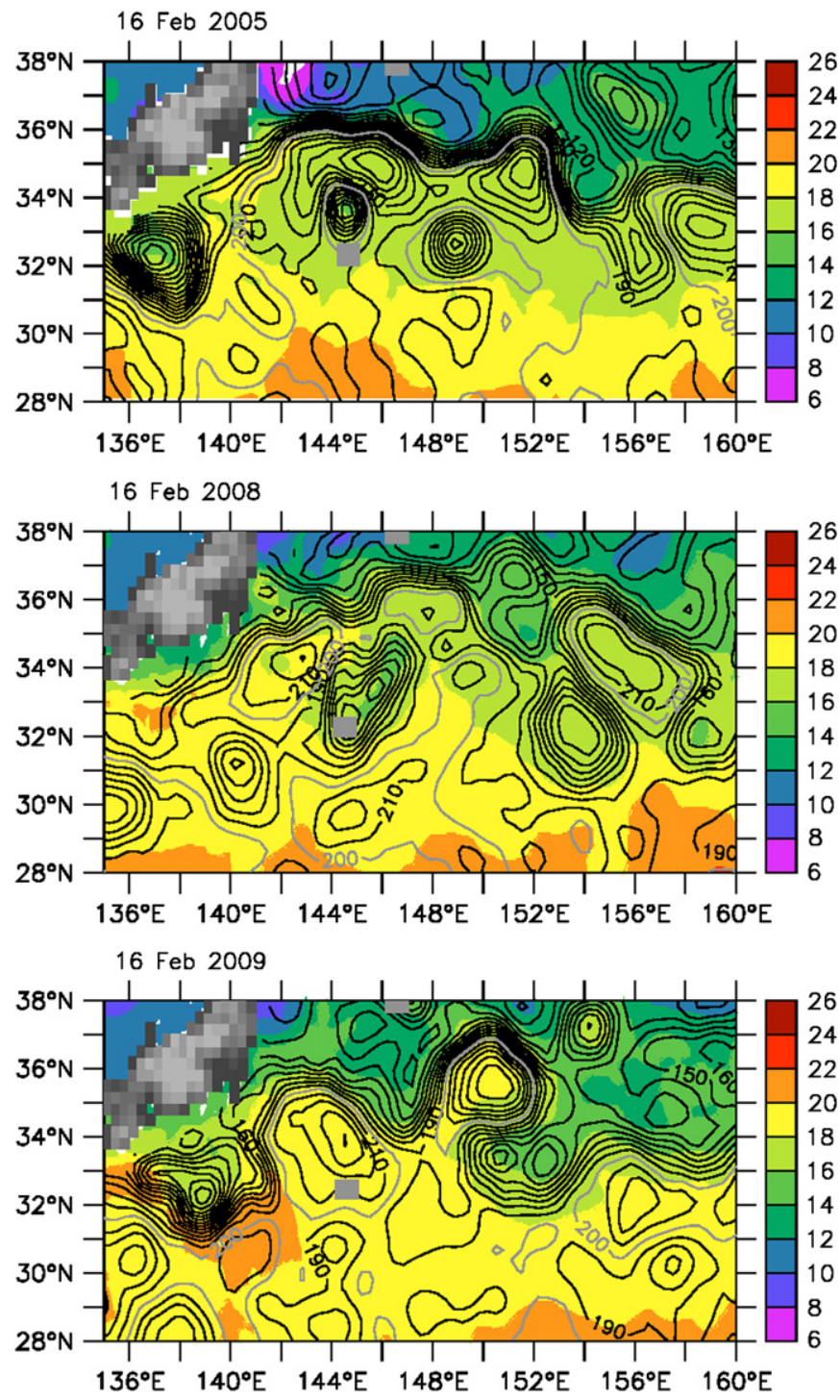

Fig. 1. Sea surface temperature (SST) and absolute sea surface height (SSH) for 16 February 2005, 16 February 2008, and 16 February 2009. The KEO site near $32.3^{\circ} \mathrm{N}$, $144.5^{\circ} \mathrm{E}$ is shown as a grey square. The NOAA Optimal Interpolation version 2 SST product was used for the 2005 snapshot; the Global Data Assimilation Experiment (GODAE) High Resolution SST (GHRSST) 5-km product was used for the 2008 and 2009 snapshots. The Aviso SSH anomaly is combined with the Teague et al. (1990) mean SSH to produce the absolute SSH. The $200 \mathrm{~cm}$ SSH contour is highlighted in grey.

complete: Period 1 (18 July 2004-17 July 2005) when the KE was quasi-stable and Period 2 (1 November 2007-31 October 2008) when the KE was unstable.

The nominal location of the mooring is $32.3^{\circ} \mathrm{N}, 144.5^{\circ} \mathrm{E}$. However, in order for the mooring to survive the strong currents, the scope of the mooring is large (mooring line/water depth $\sim 1.4$ ) and thus the buoy watch circle has a radius of $6 \mathrm{~km}$. More importantly, the anchor position varied from deployment to deployment, causing the buoy position to vary by up to $41 \mathrm{~km}$. Thus the daily buoy position from Service Argos is used to determine co-located satellite and other measurements.

The KEO mooring surface measurements include: wind speed and direction (from a sonic anemometer), air temperature and relative humidity, barometric pressure, rain rate, solar and long-wave radiation, and SST and salinity at $1 \mathrm{~m}$ depth (Fig. 2). All meteorological and subsurface temperature and salinity measurements have a 10-min resolution, with the exception of radiation ( $2 \mathrm{~min}$ resolution). In particular, all meteorological measurements except rain are 2 min averages of $1 \mathrm{~Hz}$ or faster samples. $10 \mathrm{~min}$ averaged rain rate is computed from $1 \mathrm{~min}$ resolution rain accumulations. Uncertainties in meteorological measurements are described in Kubota et al. (2008).

These data are used to compute the net surface heat flux, $Q_{0}$ (Fig. 3), following Cronin et al. (2006), where:

$$
\begin{aligned}
Q_{0} & =((1-\alpha) S W R)+\left(\varepsilon\left(L W R-\sigma T_{s}^{4}\right)\right)-Q_{\text {lat }}-Q_{\text {sen }} \\
& =Q_{s w}-Q_{l w}-Q_{\text {lat }}-Q_{\text {sen }}
\end{aligned}
$$

The net solar radiation $\left(Q_{s w}\right)$ is estimated from the measured downwelling shortwave radiation (SWR) and a climatological monthly surface albedo $(\alpha)$ estimated from the International Satellite Cloud Climatology Project (http://isccp.giss.nasa.gov/ products/browsesurf1.html). The net longwave radiation $\left(Q_{l w}\right)$ is estimated as the difference between the outgoing black-body radiation at the skin temperature $\left(T_{s}\right)$ in degrees Kelvin and the measured downwelling longwave radiation (LWR), where emissivity $(\varepsilon)$ is assumed to be 0.98 . The latent $\left(Q_{\text {lat }}\right)$ and sensible $\left(Q_{\text {sen }}\right)$ heat fluxes are computed using the COARE v3.0 bulk algorithm (Fairall et al., 2003) with hourly averaged data and include skintemperature corrections to the 1-m SST. The amount of solar radiation that penetrates through the base of the mixed layer depth $\left(Q_{p e n}\right.$ in Eq. (2)) is estimated as $0.38 Q_{s w} \exp (-h \lambda)$, where the extinction coefficient $\lambda^{-1}$ is assumed to be $20 \mathrm{~m}$ consistent with Jerlov Type 1A water (Paulson and Simpson, 1977).

Temperature was measured at up to 26 depths down to $525 \mathrm{~m}$ (Fig. 4), while salinity was measured at a subset of these depths. Because the mooring was a slack-line mooring, the measured pressure (rather than the line depth) was used to determine the depths of the subsurface sensors. The measurements were then regridded to nominal depths by assuming a constant wire angle between each pressure sensor. Two large data gaps exist due to mooring failure. The first break occurred in November 2005 below the deepest sensor, and all sensors were recovered. In contrast, the wire break in April 2007 occurred at the buoy bridle, apparently due to fishing vandalism, and all subsurface sensors were lost. Thus from June 2006 to May 2007, only telemetered daily-averaged subsurface data can be used. Due to reduced accuracy of the heat content and mixed layer estimates, we use data from this period with caution.

Following de Boyer Montégut et al. (2004) and Oka et al. (2007), we define the Mixed Layer Depth (MLD), i.e., $h$ in Eq. (2), as the depth where the daily-averaged temperature is $0.2^{\circ} \mathrm{C}$ cooler than at $10 \mathrm{~m}$. This definition guarantees that the mixed layer is at least $10 \mathrm{~m}$ thick and has a temperature that is similar to the SST. As shown by Qiu et al. (2006), in this region, the stratification of the seasonal pycnocline is primarily associated with temperature and therefore this temperature-based MLD will be nearly equivalent to one based upon density. Salinity data, however, are used in combination with the temperature data to compute the buoyancy frequency and the Richardson number in the $20 \mathrm{~m}$ layer below the base of the mixed layer.

We also use temperature data from Argo floats that were deployed during, prior to, and following the KESS experiment (Oka and Suga, 2003; Qiu et al., 2006) to construct a time series of the ambient stratification and vertically averaged temperature of the RG (Fig. 4). In particular, we used float profiles whose coincident absolute sea surface height (described below) is greater than $2 \mathrm{~m}$ to compute the ambient RG temperature and salinity profiles as was done by Qiu et al. (2006). This criterion rejects floats that are either outside of the RG or are within coldcore eddies in the RG. We therefore interpret this composite time series as being representative of the "ambient" stratification in 

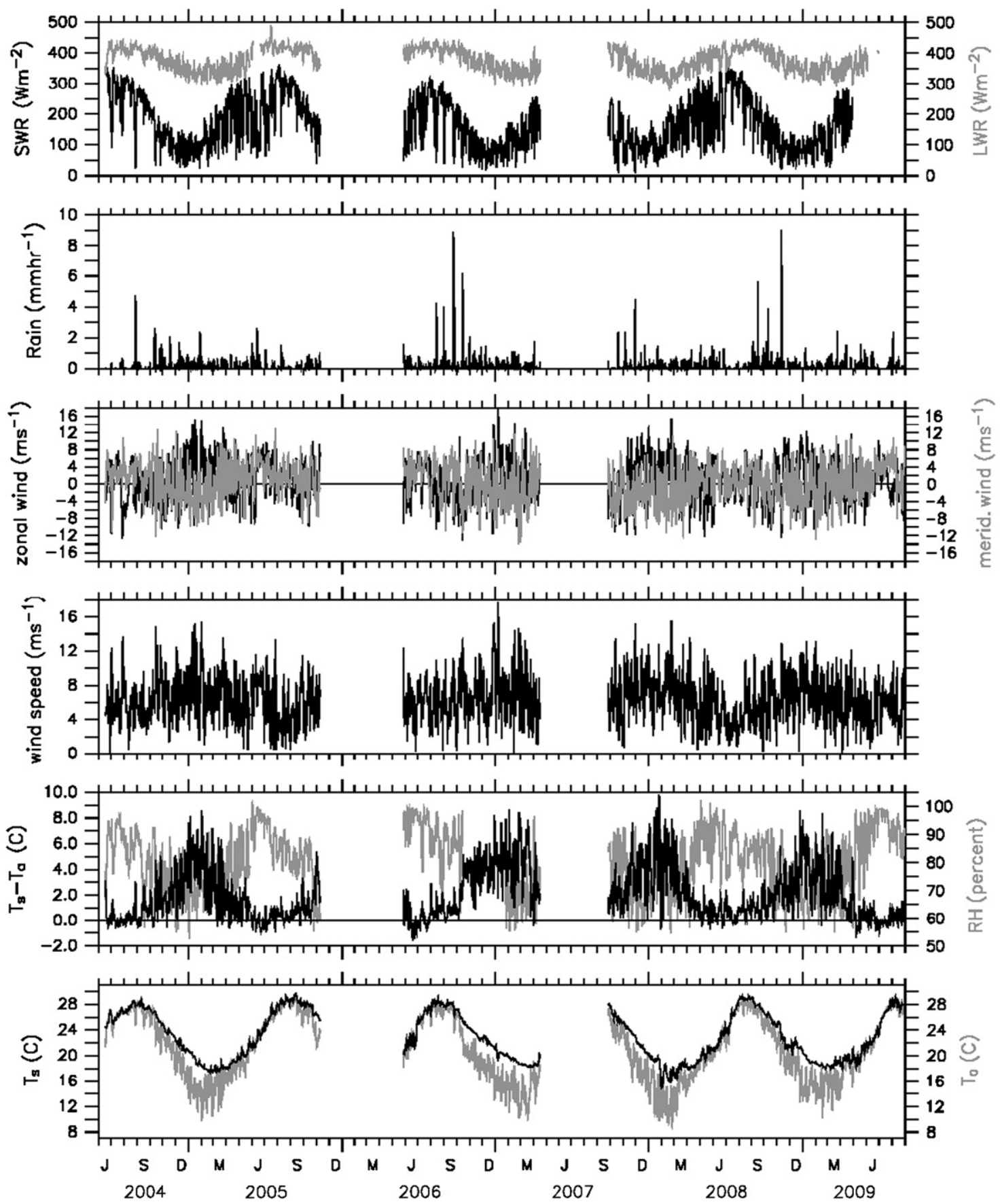

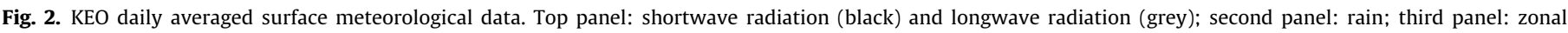

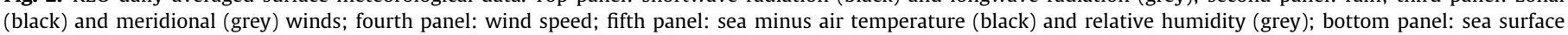
temperature (black) and air temperature (grey). The left and right axes show the scale for the variables shown in respectively black and grey.

the RG, the stratification the KEO would observe in the absence of cold-core eddies.

The Argo float composite time series is only used in the evaluation of the $250 \mathrm{~m}$ heat content budget Eq. (1). In this budget, the horizontal advection (term in parentheses in Eq. (1)) is estimated as a residual. In contrast, for the mixed layer temperature budget Eq. (2), advection is estimated at the KEO mooring and vertical diffusive mixing is estimated as the residual. To compute horizontal temperature advection at KEO, the vertically averaged mixed layer velocity $\left(u_{a}\right)$ is estimated from a moored Acoustic Doppler Current Profiler (ADCP) and current meters. In particular, from June 2004 to June 2006, Pacific Marine Environmental Laboratory (PMEL) had an upward-looking $150-\mathrm{kHz}$ ADCP on the nearby KESS subsurface mooring that profiled the horizontal currents between roughly $250 \mathrm{~m}$ and $50 \mathrm{~m}$ in $10 \mathrm{~m}$ bins. Beginning in June 2005, near-surface acoustic Doppler current meters were attached to the KEO mooring line to have their bin centered at $5 \mathrm{~m}$ (or $6 \mathrm{~m}$ ), $15 \mathrm{~m}$, and $35 \mathrm{~m}$ (or $36 \mathrm{~m}$ ) (Fig. 6). Due to sensor malfunction, there are some significant data gaps in these current meter records. When the mixed layer depth was below the deepest current measurement, currents were extrapolated by assuming there was no shear within the mixed layer. The error associated with the extrapolation is discussed in Appendix 1.

The mixed layer velocity time series was then combined with the SST gradient evaluated at KEO to obtain the horizontal mixed layer temperature advection in Eq. (2). The SST gradient was 

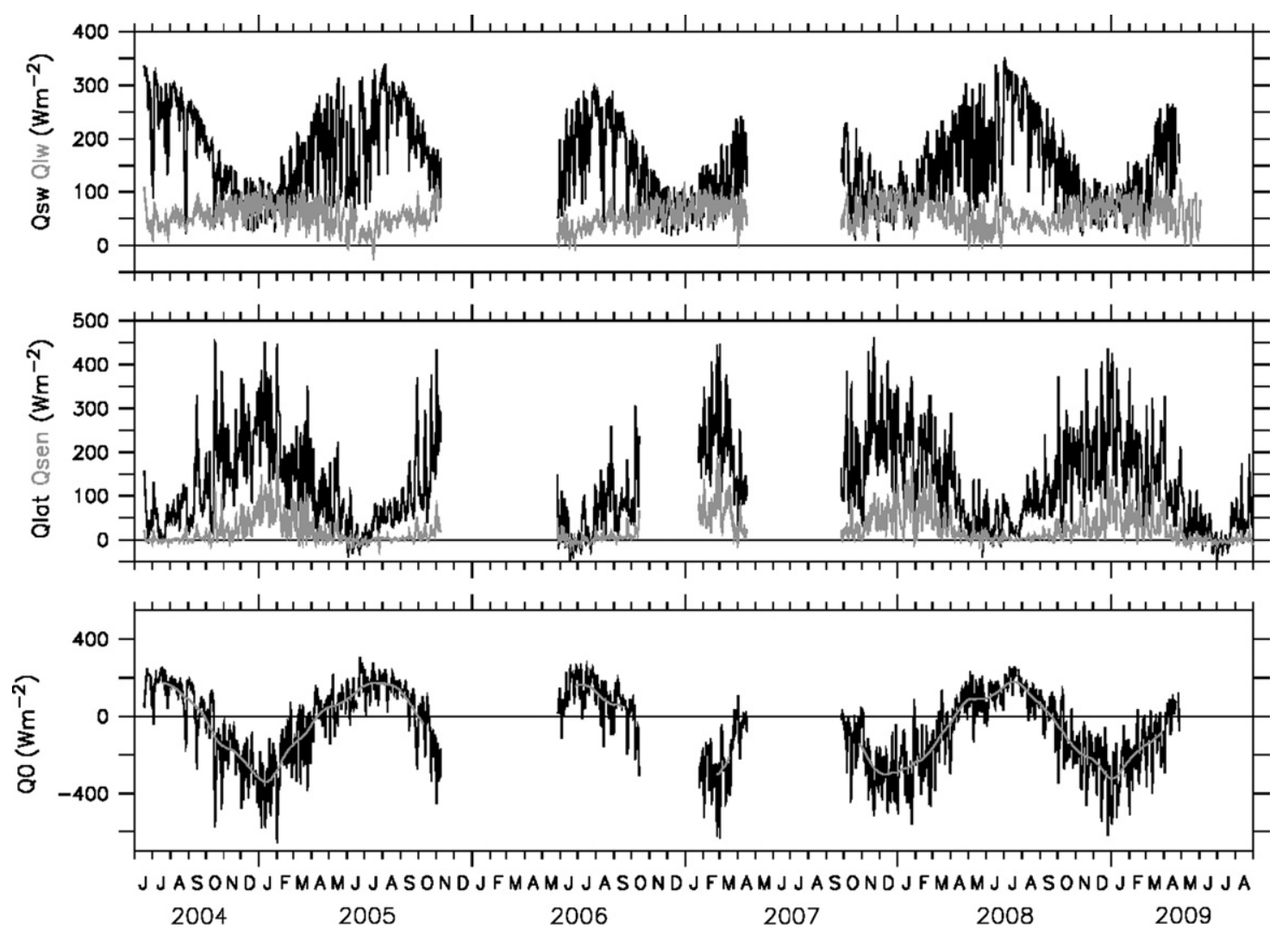

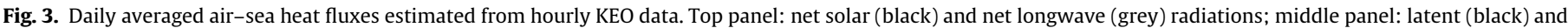
sensible (grey) heat loss; and bottom panel: daily averaged (black) and 61-day smoothed (grey) net surface heat flux into the ocean.

estimated from the $1 / 4$ degree NOAA Optimal Interpolation daily SST version 2 product that blends Advanced Very High Resolution Radiometer and Advanced Microwave Scanning Radiometer satellite data (Reynolds et al., 2007) for the period up to April 2006, at which point the Global Data Assimilation Experiment (GODAE) High Resolution Sea Surface Temperature (GHRSST) $5 \mathrm{~km}$ product (Stark et al., 2007) becomes available and was used. Because the advective length scale for one day is roughly $45 \mathrm{~km}$, the GHRSST product was smoothed with a 9-point boxcar filter, and then sub-sampled to a $25 \mathrm{~km}$ grid before horizontal gradients were computed.

To estimate vertical advection in Eqs. (1) and (2), vertical velocity at the base of the mixed layer was estimated from the Sverdrup balance with the assumption that the turbulent stress vanishes at the MLD:

$w_{-h}=-\frac{\beta g h}{f^{2}} \frac{\partial \eta}{\partial x}+\frac{1}{\rho f} \nabla \times \tau+\frac{\beta}{\rho f^{2}} \tau^{x}$

where $f$ is the planetary Coriolis parameter, $\beta$ is the meridional gradient in $f, \eta$ is the sea level height, $\tau$ is the wind stress vector, and $\tau^{x}$ is the zonal component of the wind stress. Note that the subsurface pressure gradient is assumed to be due entirely to sea level topography, so that the geostrophic velocity is uniform within the layer. Aviso-merged anomalous Sea Surface Height (SSH) fields with the Teague et al. (1990) mean SSH are used to evaluate the first term on the rhs of Eq. (4). Wind stress curl and zonal wind stress at the KEO site are estimated from the daily gridded QuikScat mean wind field product. To estimate vertical velocity at $250 \mathrm{~m}$, we assume that $w$ is zero at the surface and uniform between the base of the mixed layer and the top of the main thermocline. No attempt is made to estimate vertical motion associated with baroclinic instability or other mesoscale processes. It should be noted that vertical and horizontal velocities are related dynamically through continuity and thus vertical and horizontal advection of heat are also dynamically related.

The $250 \mathrm{~m}$ level is generally within the STMW (Fig. 4). If temperature is vertically uniform at this level, then diffusive mixing is expected to be negligible, and horizontal advection within the $250 \mathrm{~m}$ layer can be estimated as a residual of Eq. (1). However since the temperature is often weakly stratified at this level, it is likely that diffusive mixing contributes to the residual and acts to cool the layer, particularly during winter when the diffusivity appears to be very large, as will be discussed in Section 4.2. In this case, it is likely that the actual heat advection is more effective at warming the layer than is inferred from the residual of (1). In the mixed layer temperature balance Eq. (2), horizontal advection is directly estimated and diffusive mixing at the base of the mixed layer is estimated as a residual of the budget Eq. (2). These residuals, however, also include the accumulation of all errors. A complete accounting of the uncertainties in the diffusivity estimate is included in Appendix 1.

\section{Results}

\subsection{Seasonal thermocline heat content}

To address the question of whether the heat content within the seasonal thermocline is controlled primarily by the intraseasonal and seasonal variations in the net surface heat flux, we evaluate Eq. (1), the heat budget for the top $250 \mathrm{~m}$ layer. The entire seasonal thermocline lies within this layer (Fig. 4); temperature is relatively uniform at $250 \mathrm{~m}$. We thus refer to this budget as the "seasonal thermocline heat budget". As shown in Figs. 4 and 6 , both the ambient RG and local KEO seasonal 


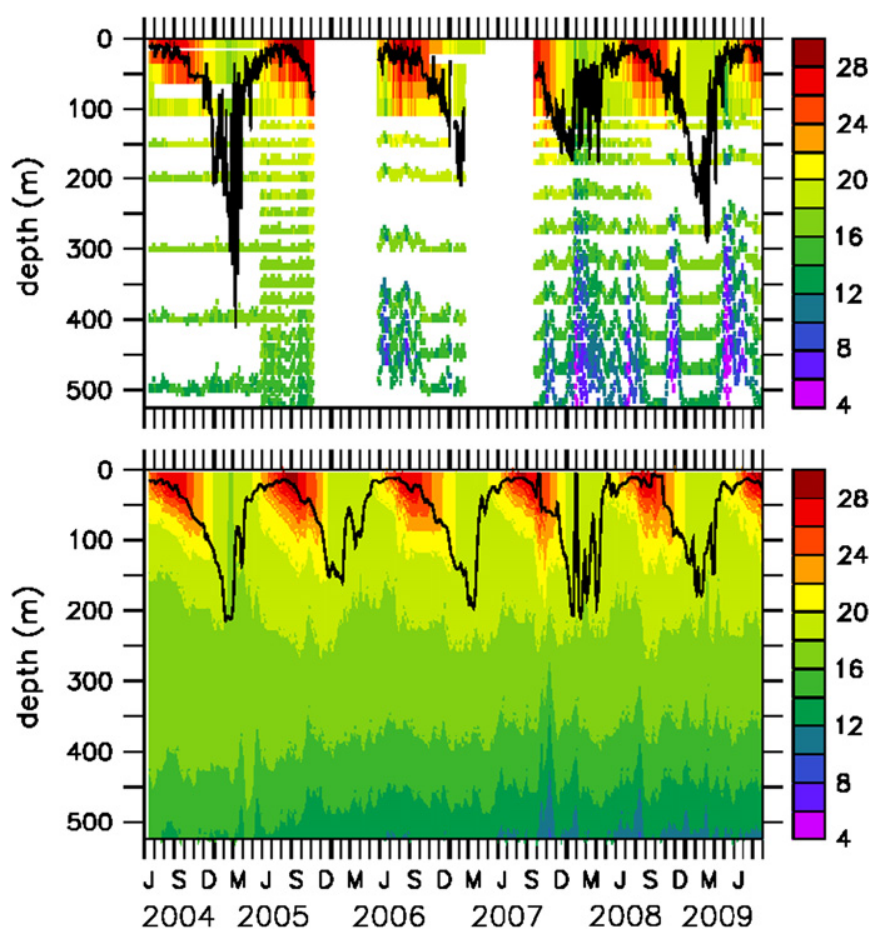

Fig. 4. KEO daily averaged subsurface temperature (upper panel) and Argo composite temperature (bottom panel) in units ${ }^{\circ} \mathrm{C}$. Following methodology of Qiu et al. (2006), only floats within the KESS region whose coincident sea surface height anomaly is greater than $2 \mathrm{~m}$ are used in the composite. The black line in each panel is the mixed layer depth estimated for the corresponding temperature stratification.

thermocline heat content have large seasonal and interannual variability: Their heat content begin to decrease (i.e., cool) in late September-early October. Cooling (indicated by a negative tendency rate in Fig. 6) continues until February-March, at which point the MLD begins to shoal. The seasonal thermocline is reestablished in May. Marking the shift in the KE system from its quasi-stable state to its unstable state, both the Argo and KEO time series show the main thermocline began to rise in mid-late 2005, after which the moored time series shows significantly more variability and intense currents due to the passage of eddies and interaction with the jet (Figs. 4 and 5).

The seasonal heat content loss and gain roughly correspond to the surface heat flux out of and into the ocean, with a crosscorrelation of 0.68 for the local balance and 0.90 for the ambient RG balance (Fig. 6, Table 1). The very large net surface heat loss observed in this region occurs October through March, when the solar radiation is small and latent and sensible heat fluxes are large (Figs. 2 and 3). As discussed by Bond and Cronin (2008) and Konda et al. (2010), the large latent and sensible heat fluxes are associated with cold-air outbreaks of continental origin and low pressure systems, typically over the Kamchatka Peninsula. During these events, winds with a strong northerly component bring cold and dry air over the relatively warm $\mathrm{KE}$ water, causing air-sea temperature differences of up to $8{ }^{\circ} \mathrm{C}$ (Fig. 2).

In contrast, during the warm season (June-August), solar radiation is roughly twice as large as the combined remaining surface heat flux terms (Fig. 3); the net surface heat flux warms the ocean. The more-or-less steady warming by the sun in summer is punctuated by short periods of thick and persistent clouds, sometimes accompanied by high winds associated with the northward passage of tropical cyclones (typhoons) (Bond and Cronin, 2008; Bond et al., 2011; Tomita et al., 2010). During these periods, typically lasting a few days, the net shortwave fluxes can be on the order of $200 \mathrm{~W} / \mathrm{m}^{2}$ less than usual and sustained daily-
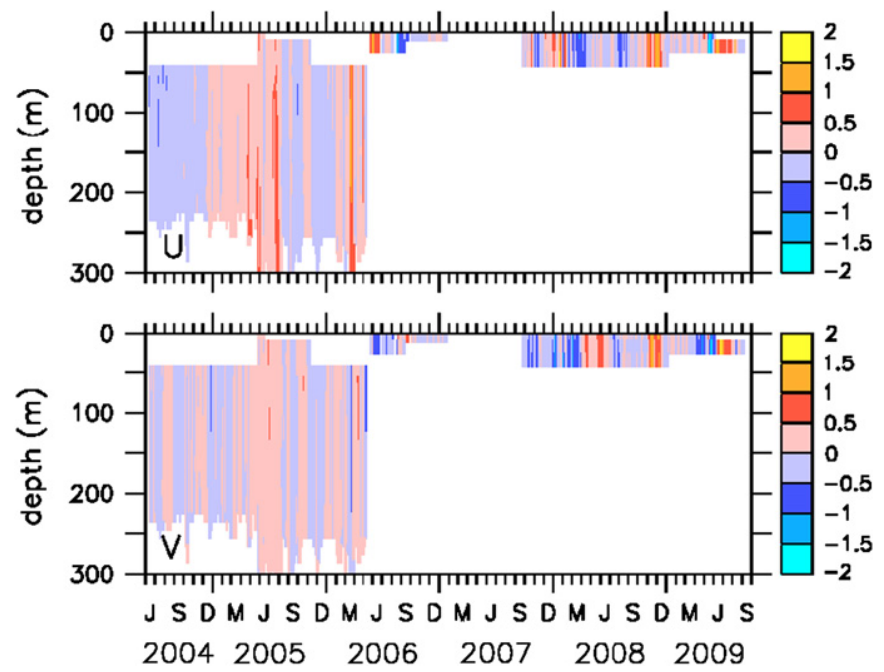

Fig. 5. KEO daily-averaged zonal (upper panel) and meridional (bottom panel) currents. Units are $\mathrm{m} / \mathrm{s}$.

averaged winds can be more than $12 \mathrm{~m} / \mathrm{s}$. On average, a tropical cyclone crosses the $30^{\circ} \mathrm{N}$ latitude in the western North Pacific roughly every 3 weeks during typhoon season (Bond et al., 2010). Thus while these events are short-lived, their ubiquity affects the seasonal and interannual variability, and as will be discussed later, contributes to the large diffusive mixing in this region.

During Period 1 ( 18 July 2004-17 July 2005), vertical advection was very weak, causing on average $8 \mathrm{~W} / \mathrm{m}^{2}$ of warming in the upper $250 \mathrm{~m}$ (Table 1 ). In contrast, during the winter of 2008, the strong geostrophic currents at KEO were southward, resulting in upwelling at KEO and a net cooling during Period 2 (1 November 2007-31 October 2008) of $-49 \mathrm{~W} / \mathrm{m}^{2}$ in the local balance, and $-35 \mathrm{~W} / \mathrm{m}^{2}$ in the RG balance. Overall, vertical advection had the largest change between Period 1 and 2 and thus appears to be an important process controlling interannual variability of the seasonal thermocline heat content.

The primary process affecting the seasonal variations in the RG heat content is the net surface heat flux. While the general timing of the shift in sign of the heat content tendency rate corresponds to the shift in sign of the net surface heat flux, the exact timing can differ by more than a month, particularly in spring. For example, while the heat content begins to increase in early March, the net surface heat flux shifts from cooling to warming the ocean one to two months later (in April).

Horizontal advection, estimated as a residual of Eq. (1), tends to warm the upper $250 \mathrm{~m}$ and may be responsible for the early spring restratification. Unlike horizontal advection in the ambient RG, which is nearly always a warming term, local horizontal advection at KEO has large fluctuations associated with the passage of eddies and jet meanders that have a strong influence on the local heat content (Table 1). As discussed earlier, the cooling effect of diffusive mixing is also included in the residual, and therefore the heat advection estimated from the residual is expected to underestimate the overall warming due to horizontal advection.

When averaged over the 1-year periods, however, the eddy effects tend to cancel out. Likewise, the mean advection for the local KEO and the ambient RG budgets were quite similar during both periods (Table 1). These results suggest that the influence of eddies is likely incorporated into the ambient stratification over the 1 year timescale, and that there may be compensating effects (e.g. between horizontal advection and diffusion across the $250 \mathrm{~m}$ level, or between horizontal advection by the vertically averaged flow and heat convergence by the sheared, stratified flow) occurring on interannual timescales. 

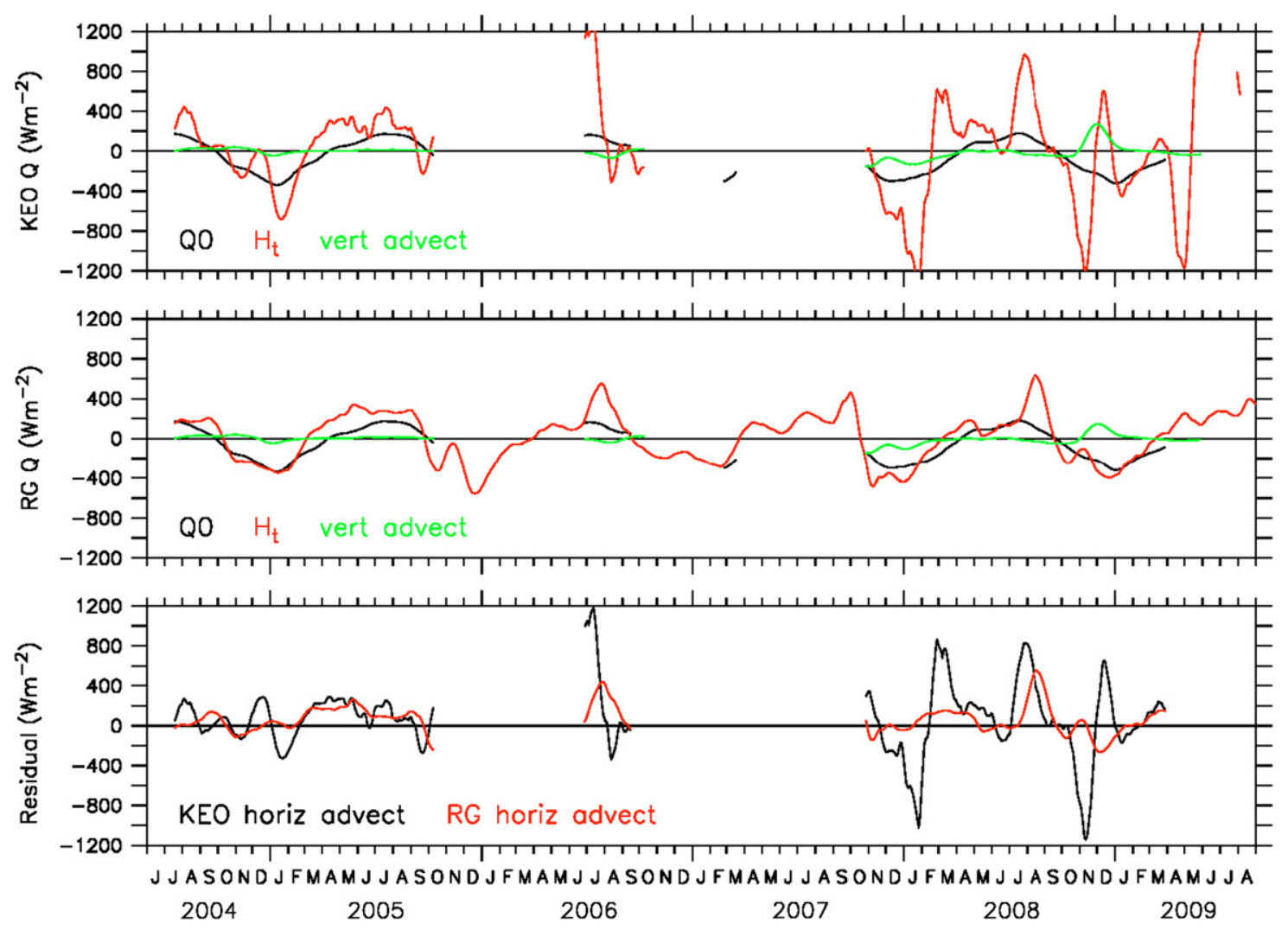

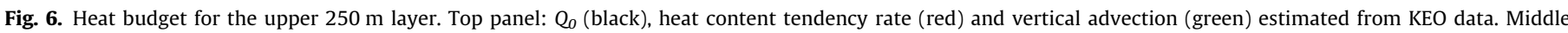

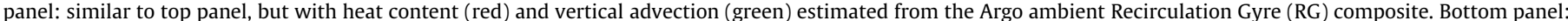

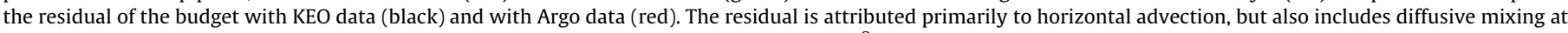
$250 \mathrm{~m}$ and errors. All terms are filtered with a 61-day triangular filter and have units $\mathrm{Wm}^{-2}$.

Table 1

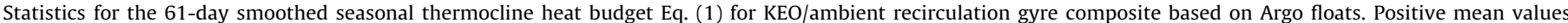

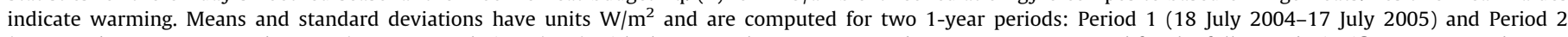

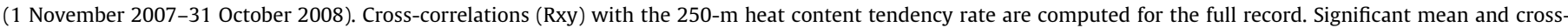
correlation values at the 95\% level are in bold. Degrees of freedom are estimated based upon a zero-crossing correlation time-scale.

\begin{tabular}{|c|c|c|c|c|c|}
\hline & \multicolumn{2}{|l|}{ Period 1} & \multicolumn{2}{|l|}{ Period 2} & \multirow{2}{*}{$\begin{array}{l}\text { Full } \\
\text { Rxy }\end{array}$} \\
\hline & Mean & Std & Mean & Std & \\
\hline Heat Content tendency rate & $35 / 25$ & $285 / 229$ & $-36 /-22$ & $535 / 283$ & 1 \\
\hline$Q_{0}$ & $-53 /-53$ & $161 / 161$ & $-55 /-55$ & $162 / 161$ & $0.68 / 0.90$ \\
\hline Vertical advection & $8 / 8$ & $21 / 21$ & $-49 /-35$ & $46 / 37$ & $0.17 / 0.11$ \\
\hline Horizontal advection & $80 / 70$ & $160 / 95$ & $68 / 69$ & $406 / 153$ & $0.93 / 0.79$ \\
\hline
\end{tabular}

Table 2

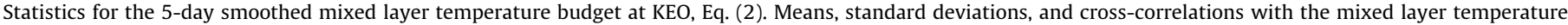

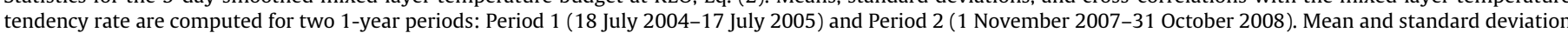
values have units ${ }^{\circ} \mathrm{C}$ /day. Significant mean and cross-correlation values at the $95 \%$ level are in bold.

\begin{tabular}{|c|c|c|c|c|c|c|}
\hline & \multicolumn{3}{|l|}{ Period 1} & \multicolumn{3}{|l|}{ Period 2} \\
\hline & Mean & Std & $\mathbf{R x y}$ & Mean & Std & Rxy \\
\hline$T_{a}$ tendency rate & $0.2 \times 10^{-2}$ & $13 \times 10^{-2}$ & 1 & $-0.1 \times 10^{-2}$ & $18 \times 10^{-2}$ & 1 \\
\hline Due to $Q_{0}-Q_{\text {pen }}$ & $1.7 \times 10^{-2}$ & $9 \times 10^{-2}$ & 0.57 & $1.8 \times 10^{-2}$ & $9 \times 10^{-2}$ & 0.42 \\
\hline Due to horizontal advection & $0.5 \times 10^{-2}$ & $8 \times 10^{-2}$ & 0.38 & $-2.2 \times 10^{-2}$ & $20 \times 10^{-2}$ & -0.43 \\
\hline Due to (de/en)trainment & $0.9 \times 10^{-3}$ & $3 \times 10^{-2}$ & 0.36 & $0.6 \times 10^{-2}$ & $2 \times 10^{-2}$ & 0 \\
\hline Resid (diffusion and errors) & $-3.0 \times 10^{-2}$ & $11 \times 10^{-2}$ & 0.28 & $-0.2 \times 10^{-2}$ & $32 \times 10^{-2}$ & 0.71 \\
\hline
\end{tabular}

\subsection{Surface mixed layer temperature budget}

To evaluate the processes affecting the vertical distribution of heat within the water column we evaluate the mixed layer temperature budget Eq. (2), smoothing each term with a 5-day triangular filter as discussed in Section 2. While all terms in the budget are significantly correlated with the mixed layer temperature tendency rate (Table 2), not surprisingly, the surface heat flux 
absorbed within the mixed layer has the strongest influence on the mixed layer temperature, particularly during summer when the MLD is shallow (Figs. 4 and 7). The effect of the MLD variability on the efficiency of surface heat fluxes at changing mixed layer temperature has been noted by numerous authors (e.g., Cronin and McPhaden, 1997; Kako and Kubota, 2007; Qiu and Kelly, 1993; Tomita et al., 2010; Vivier et al., 2002). This effect has such a large influence in this region that while the 1-year average net surface heat flux is out of the ocean (Table 1 ), the net effect of the surface heat flux is to warm the mixed layer (Table 2). During summertime when the ocean is heated, the mixed layer is shallow (generally above $20 \mathrm{~m}$ ), and thus the thermal inertia of this layer is low, causing the SST to respond rapidly. In contrast, during wintertime when the ocean loses heat to the atmosphere, the MLD can be as deep as $400 \mathrm{~m}$, and thus the thermal inertia of the layer is very large, causing the SST changes to be small (Figs. 2 and 4 ).

In addition to the seasonal variations, MLD also varies on interannual time scales. Wintertime MLD was deepest in February 2005 (Fig. 4). After 2005 when the KE system entered its unstable state, the wintertime mixed layer was significantly thinner and was never more than $200 \mathrm{~m}$ thick. During the unstable regime, the jet was shifted southward and had large meanders. Consequently, KEO was occasionally within the jet where the main thermocline is shallower. Qiu et al. (2007) have shown that some of the shoaling in the wintertime MLD within the RG is due to remotely-forced Rossby Waves. It should be noted that while cold-core eddies would cause the mixed layer to be shallower than the ambient water, the deepest MLD are found in the mooring time series. These very deep MLDs generally lasted only a few days in the mooring time series but are not in the Argo composite time series. This may be because the 5-day sampling used for the KESS Argo floats and 10-day sampling for standard floats are not sufficient to capture these events. Likewise, if these events are spatially inhomogeous, the composite averaging would reduce these maximum depths.

As with the local $250 \mathrm{~m}$ heat content balance, mixed layer advection has significant sub-seasonal variability associated with eddies and jet meanders near KEO that is correlated with changes in the mixed layer temperature (Table 2). As expected, based upon the generally higher eddy activity present when the KE system is in its unstable regime during Period 2, the standard deviation of the horizontal advection term in Eq. (2) (Fig. 7) was roughly more than double the standard deviation during Period 1
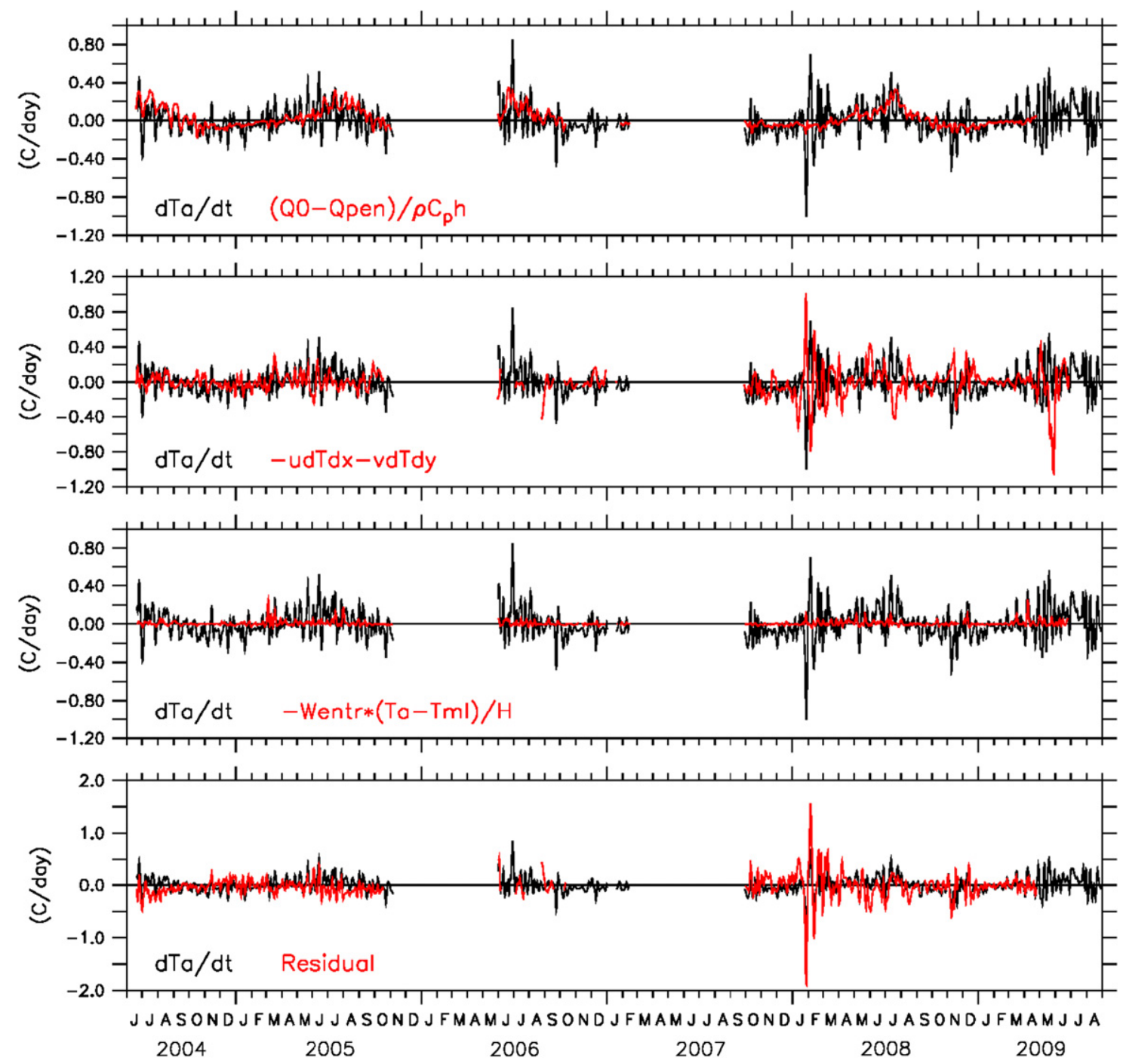

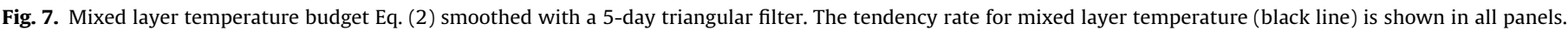

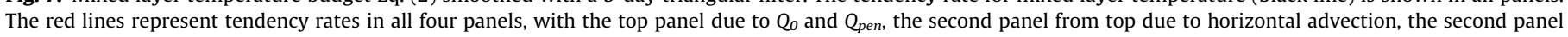

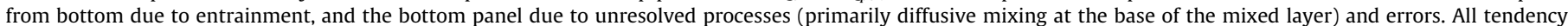
rates have units ${ }^{\circ} \mathrm{C}$ per day. 
(Table 2). It is curious that while the (residual) advection within the $250 \mathrm{~m}$ layer is a warming effect for both periods, mean advection in the mixed layer during Period 2 is a cooling effect and is anti-correlated with the tendency rate. This difference may be due to the stratified shear flow convergence, which is included in the residual of both Eqs. (1) and (2). In other words, the stratified shear flow convergence is included in the residual horizontal advection in the heat budget for the upper $250 \mathrm{~m}$, but is not included in the estimate of the horizontal advection of the mixed layer temperature balance. As a consequence, it is likely that this unresolved advective process contributes substantially to the residual during Period 2.

In our mixed layer temperature budget formulation (Eq. (2)) we make a distinction between entrainment mixing and diffusive mixing. Entrainment mixing causes the mixed layer to cool and deepen, without changing the properties below the mixed layer. Vertical diffusion, in contrast, causes the mixed layer to cool and the deeper water to warm, without necessarily changing the depth of the mixed layer. While diabatic deepening of the mixed layer, which results in entrainment, is driven by turbulent processes, diabatic shoaling, referred to as "detrainment", is not. Both effects are included in our mixed layer temperature balance Eq. (2). In fact, because the MLD can shoal by over $100 \mathrm{~m}$ in a day during spring, while entrainment mixing generally causes mixed layer deepening of tens of meter during fall, warming due to detrainment dominates over entrainment cooling (Fig. 7; Table 2).

The residual of the mixed layer temperature balance (Fig. 7; Eq. (2)) can be interpreted as being due to unresolved processes (e.g., diffusive mixing) and errors. As discussed previously, during the periods of strong advection such as observed during Period 2, we believe that the unresolved convergence of heat by stratified sheared flow may dominate the residual and is on average a warming term. Unresolved vertical diffusive mixing, on the other hand, would always be a cooling effect on the mixed layer temperature since the temperature just below the mixed layer always decreases with depth on these timescales. Thus, we will only attempt to interpret the residual as diffusive mixing when the residual is negative and when advection is believed to be small (i.e., when the estimated advection is less than one standard deviation from zero). The inferred diffusivity at the base of the mixed layer (Fig. 8) is large and has a seasonal cycle that is so large, it is best displayed on a log scale.

A careful error analysis (see Appendix 1) shows that the errors increase during winter when $h$, the error in $h$, and $(\partial T / \partial z)^{-1}$ are larger (Fig. 8). We thus must view these very large winter diffusivity values with caution. We proceed by asking why the inferred diffusivity values are so large in this region, and what may cause a seasonality in these values.
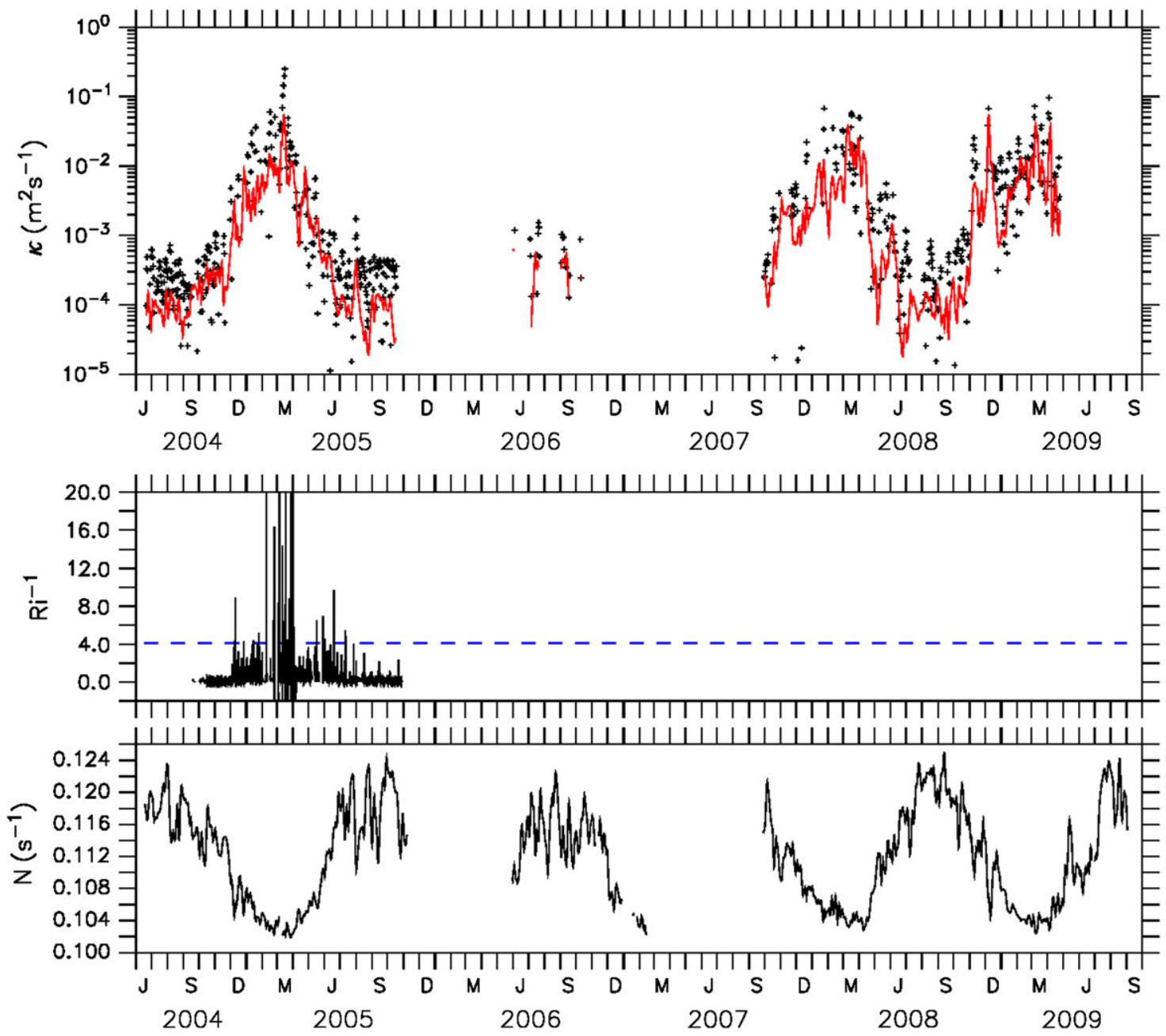

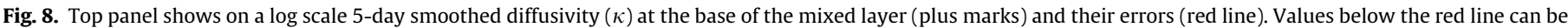

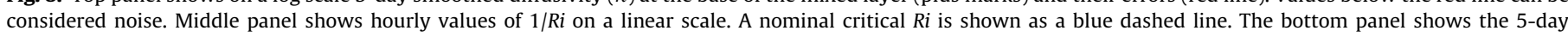

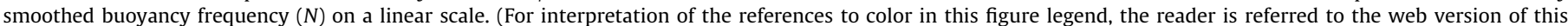
article.) 

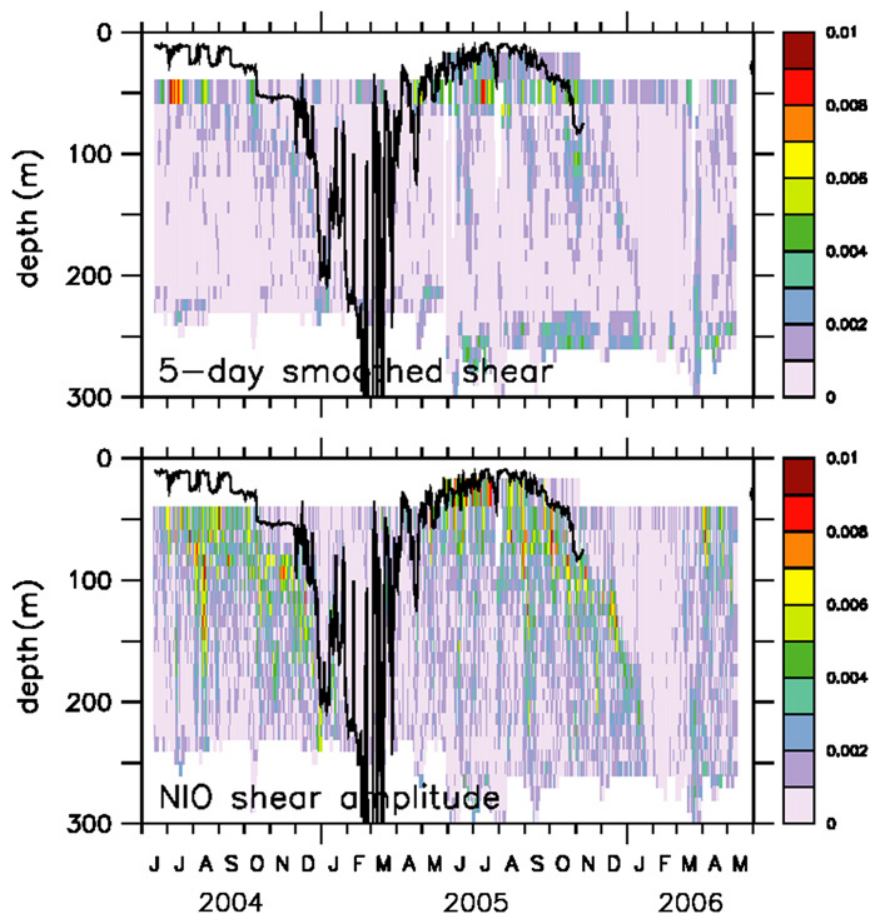

Fig. 9. Top panel shows the 5-day smoothed shear. Bottom panel shows the amplitude of the shear near the inertial oscillation frequency, estimated from a complex demodulation. In both panels, shear has units $\mathrm{s}^{-1}$ and the daily mixed layer depth is shown as a black line.

Assuming the vertical diffusive mixing occurs through shear instability, large diffusivity values might be expected when the Richardson number $\left(R i=N^{2} / S^{2}\right)$ is below a critical value of approximately $1 / 4$. Fig. 8 shows the $R i^{-1}$ estimated from hourly KESS ADCP and KEO stratification data. While the estimate is limited to times when the MLD was greater than $50 \mathrm{~m}$ and less than $250 \mathrm{~m}$ during 2004 and 2005, and the $N^{2}$ and $S^{2}$ are necessarily underestimated by our discrete sample depths, the Ri appears to reach critical levels during winter.

The vertical shear in the horizontal velocity at the base of the mixed layer (Fig. 9) is weakest in April, but otherwise appears to be quite strong throughout the year. In particular, the amplitude of shear oscillating at the inertial frequency found through complex demodulation (Fig. 9) is large throughout most the year, in all likelihood due to the passage of winter storms (D'Asaro, 1985) and summer tropical cyclones (Bond et al., 2011; Morozov and Velarde, 2008; Price, 1983). The large shears near the inertial frequency and at longer timescales are likely responsible for the enhanced mixing and diffusivity values found at KEO.

Because the shears are large throughout most of the year, seasonality in the diffusivity is likely caused by seasonality in the stratification. As shown in Fig. 9, during summer when the seasonal thermocline is fully formed, the stratification $(N)$ at the base of the mixed layer is very strong, while during winter when the mixed layer extends down to the top of the thermocline, $N$ is very weak. To determine an empirical power law relation between $\kappa$ and $N$, we perform a least-squares regression on the $\log$ of each (Fig. 10). The $\log (\kappa)$ and $\log (N)$ are significantly correlated, with a cross-correlation value of -0.79 . A leastsquares fit of a line to the scatter plot gives a slope of -2.5 and intercept of -7.9 , indicating that $\kappa \sim 1.3 \times 10^{-8} N^{-2.5}$. It should be noted that this is quite a bit larger than the $N^{-0.5}-N^{-1}$ dependency proposed by Gargett and Holloway (1984) for shear instability mixing. Gregg and Sanford (1988) saw no vertical dependence on $N$ in their diffusivity calculations. In contrast,

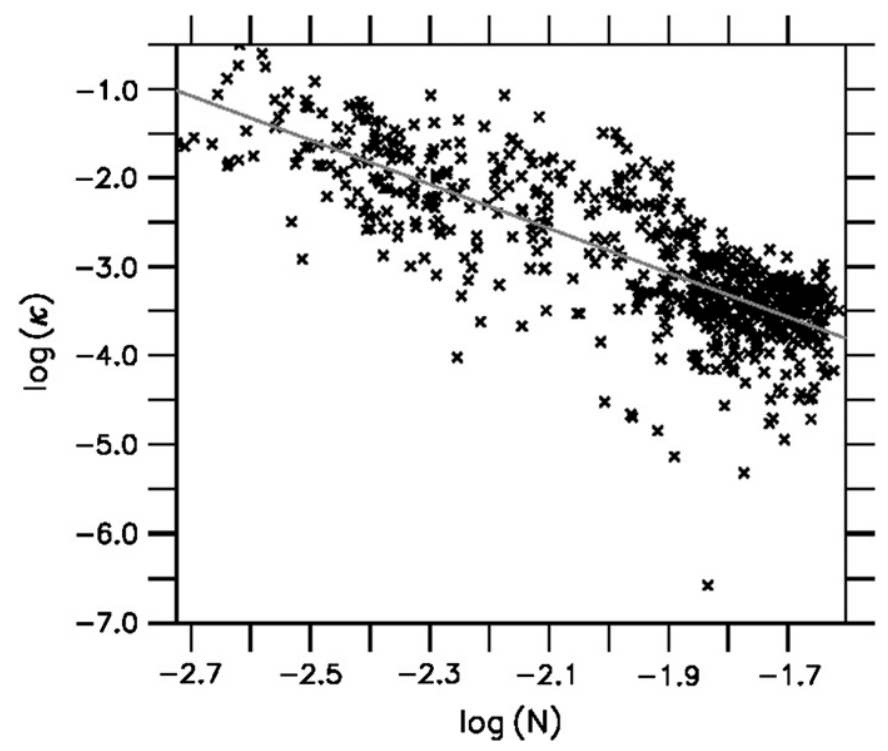

Fig. 10. $\log (\kappa)$ versus $\log (N)$ for periods when advection is less than one standard deviation from zero. The grey line is the least-squares fit, with a slope of -2.5 and intercept of -7.9 .

the strong dependence on $N$ found here reflects the temporal (seasonal) variability at the base of the mixed layer.

\subsection{One-dimensional processes affecting erosion and formation of the seasonal thermocline}

While our study suggests that the lower limit for the diffusivities at the base of the mixed layer is $3 \times 10^{-4} \mathrm{~m}^{2} / \mathrm{s}$, similar to the Qiu et al. (2006) value at the top of the STMW, microstructure measurements within the STMW (Mori et al., 2008) and in the pycnocline in the interior of the ocean (Gregg, 1989) generally have values of order $1 \times 10^{-5} \mathrm{~m}^{2} / \mathrm{s}$. In order to visualize the effect of an enhanced diffusivity value, we evaluate the Price et al. (1986) "PWP" model for the fall 2004 seasonal thermocline erosion when the heat content budget suggests that advection was relatively weak on average. To run the model, we initialize the stratification with the Argo composite profile on 26 September 2004, when the net surface heat flux began cooling the water column. The one-dimensional model is then forced with the hourly time series of wind stress, air-sea heat flux, and evaporation minus precipitation from the KEO observations for $1152 \mathrm{~h}$ (48 days). In the first run we use a vertically uniform diffusivity value of $1 \times 10^{-5} \mathrm{~m}^{2} / \mathrm{s}$; in the second run we use the $3 \times 10^{-4} \mathrm{~m}^{2}$ / $\mathrm{s}$ value. As can be seen in Fig. 11, the larger diffusivity value produces a much more realistic profile.

A similar experiment was performed for winter stratification initialized with the 1 January 2009 Argo composite. Unlike the fall runs, the winter runs were more realistic with a smaller diffusivity $\left(1 \times 10^{-5} \mathrm{~m}^{2} / \mathrm{s}\right)$ (not shown). While the upper $250 \mathrm{~m}$ heat budget indicates that advection was relatively weak during this period, this may be due to the inclusion of large diffusive mixing across a weak stratification at $250 \mathrm{~m}$. If so, the 1-dimension model with a realistic diffusivity value would not be expected to produce realistic profiles.

\section{Summary and conclusion}

In this study, data from the Kuroshio Extension Observatory (KEO) surface mooring are used to analyze upper ocean heat content and mixed layer temperature variations in the Recirculation Gyre (RG) 

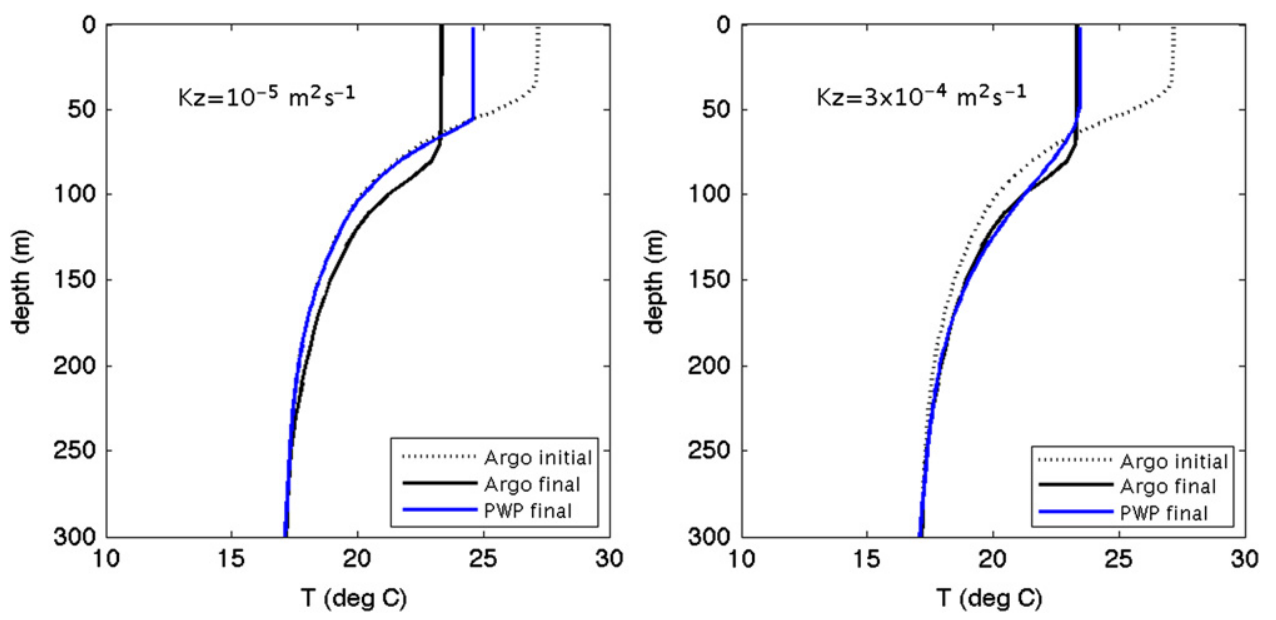

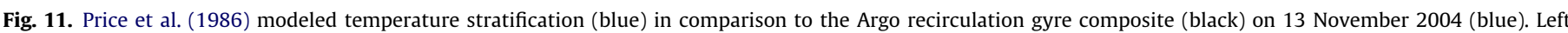

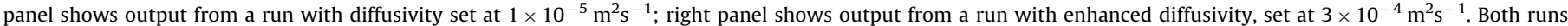
were initialized with the Argo composite from 26 September 2004 (black dotted)

south of the Kuroshio Extension (KE). During winter, cold and dry air blowing across the KE and its warm RG cause the ocean to rapidly lose heat to the atmosphere. This heat loss is responsible for the erosion of the seasonal thermocline. Furthermore, variations in the net surface heat flux strongly affect variations in upper ocean heat content (Table 1) and SST (Table 2) on seasonal and subseasonal timescales.

Heat within the upper $250 \mathrm{~m}$ is replenished through horizontal heat advection and convergence (Fig. 6; Table 1), consistent with regional heat budget analyses of Vivier et al. (2002) and Yasuda et al. (2000). Heat advection within the upper $250 \mathrm{~m}$ was estimated as a residual of the $250 \mathrm{~m}$ layer seasonal thermocline heat content budget. As found by Oka et al. (2007), horizontal heat advection appears to enable the spring restratification to begin prior to warming by the air-sea heat fluxes. In other words, the formation of the seasonal thermocline appears to occur first through horizontal processes and then through solar radiative warming. Because the restratification causes the mixed layer to be quite shallow, the thermal inertia is reduced and the surface warming and restratification is intensified. Thus, while the KE region has very large net surface heat loss when averaged over the course of a year, the net effect of the surface heat flux is to warm the mixed layer (Qiu and Kelly, 1993).

As was found by Kelly and Dong (2004) and Vivier et al. (2002), interannual variations in the heat content tendency rate appear to be controlled by advection, and not by net surface heat flux (Table 1). However, our analysis suggests that the interannual variations in vertical advection were much larger than for horizontal advection. It should be noted that our analysis had just 2 complete years, far too short to estimate the longterm mean. Averages over these 1 -year periods highlight the interannual variability in the region.

The seasonal thermocline heat budget was also evaluated using a composite ambient stratification in the RG from Argo floats within the RG that were not in cold-core eddies. When averaged over 1year periods, the residual horizontal advection in heat budget Eq. (1) using KEO data versus the Argo RG composite are nearly the same, suggesting that the influence of eddies is likely incorporated into the ambient stratification over the 1 year timescale.

While net horizontal advection within the upper $250 \mathrm{~m}$ caused warming on average, during Period 2, horizontal advection within the mixed layer was a cooling term (Tables 1 and 2). The difference appears to be resolved by considering the residual of the mixed layer temperature budget. During Period 2, the residual of the mixed layer balance was a large warming term, probably associated with the unresolved convergence of stratified shear flow. The convergence term may be particularly important near fronts where secondary circulations can cause slumping of the front or enhanced mixing depending upon the orientation of the wind relative to the front (e.g., Mahadevan et al., 2010).

The fact that the net surface heat flux on average warms the mixed layer but cools the $250 \mathrm{~m}$ layer highlights the importance of vertical transfers of heat within the water column. As the seasonal thermocline erodes, the mixed layer deepens, entraining cold water and increasing the thermal inertia of the mixed layer. Most mixed layer studies do not consider the effects of detrainment, since it is not a turbulent process. We show, however, that when averaged over the course of a year, warming due to detrainment dominates over cooling due to entrainment.

Diffusivity at the base of the mixed layer was estimated from the residual of the mixed layer temperature balance. While the values are only marginally significant during winter, the analysis suggests the presence of enhanced mixing, with diffusivity roughly $3 \times 10^{-4} \mathrm{~m}^{2} / \mathrm{s}$ during the warm season and more than two orders of magnitude larger during winter. Our warm season values are quite similar to those found at the base of the seasonal thermocline by Qiu et al. (2006) and Sukigara et al. (2011). The latter diffusivity estimate was based upon a dissolved oxygen budget analysis; the Qiu et al. (2006) estimate was based upon the potential vorticity budget of the North Pacific Subtropical Mode Water (STMW). Using microstructure measurements, Mori et al. (2008) found that within and above the core of the STMW, the microstructure diffusivity values were $\sim 10^{-5} \mathrm{~m}^{2} / \mathrm{s}$, over an order of magnitude smaller than found in our study and the budget analyses of Qiu et al. (2006) and Sukigara et al. (2011). It may be that the STMW acts as a barrier to internal wave energy and turbulent mixing, and that this trapping enhances the local dissipation in the seasonal thermocline as proposed by Qiu et al. (2006). Indeed, current meters deployed near the bottom of the ocean during KESS show that near inertial wave (NIW) energy is roughly 5 times larger north of the KE jet than south. Park et al. (2010) argue that this is primarily because the KE jet acts as a barrier to the southward propagation of NIWs, but also note that this could occur if NIW energy is dissipated higher in the water column in the RG south of the jet. Alternatively, mixing events could be episodic and difficult to capture in microstructure survey. While analysis at the base of the mixed layer was not the focus of their study, Mori et al. (2008) show diffusivities 
several orders of magnitude larger within the mixed layer which are more consistent with the mixed layer base values found in our study.

Overall, the enhanced mixing at the base of the mixed layer that was diagnosed at KEO appears to be due to the large vertical shears characteristic of the region. In particular, inertial oscillations generated by the passage of tropical cyclones during summer and, strong and more frequent storms during winter are likely to contribute to the enhanced diffusivity in the KE region. The large seasonality in diffusivity thus appears to be associated with seasonal variations in the stratification. During summertime when the seasonal thermocline is well developed, the stratification is stronger and the Richardson number at the base of the mixed layer is larger. During wintertime when the mixed layer extends down to the top of the thermocline, the stratification at the base of the mixed layer is weak and the $R i$ often reaches low values suggesting instability and turbulent mixing.

As a result of the enhanced diffusive mixing below the mixed layer, some of the mixed layer heat gets transferred downward, eroding and potentially modifying sequestered STMW and even water of the permanent thermocline during winter. If the diffusive mixing only results in a thinning of the STMW, then the mode water temperature from the previous winter will reemerge when it ventilates as proposed by Alexander and Deser (1995). However if the mode water thermal properties are modified, then the memory of the previous winter is impacted. An example of mode water modification at KEO is shown by Bond et al. (2011) in a case study of the oceanic response to the passage of a tropical cyclone.

In summary, the distribution of heat within the water column can affect the thermal inertia (efficiency of warming) and the diffusivity (efficiency of mixing). Based upon scaling arguments and a onedimensional mixed layer model, Qiu and Chen (2006) show that relative variations in $N$ are twice as effective at causing wintertime MLD variations as relative variations in $Q_{0}$. Variations in the summertime heating thus can have a strong impact on the wintertime mixed layer (Kako and Kubota, 2007; Tomita et al., 2010).

The large heat released by the KE into the atmosphere makes this a region of intense air-sea interaction. Understanding how the heat is replenished and redistributed horizontally and vertically is critical for understanding the role of the ocean in the climate system. Long-term, high-resolution observations such as those made by the KEO surface mooring can provide direct measurements for diagnosing these processes on synoptic through interannual time scales in this highly variable region.

\section{Acknowledgments}

The roots of KEO and KESS can be traced back to early work done by Tom Rossby in the Gulf Stream and the $18{ }^{\circ} \mathrm{C}$ water region of the North Atlantic. Tom has influenced the careers of nearly all authors here. It is an honor to have this paper included in this special issue as a tribute to Tom. KEO was funded by the NOAA Office of Climate Observations. We gratefully acknowledge the dedication of the PMEL Ocean Climate Station project office (http://www.pmel.noaa.gov/ $\mathrm{OCS} /$ ) and TAO personnel in maintaining the KEO mooring. Shiptime was provided by KESS in 2004-2006, and through a partnership with JAMSTEC in 2007-2009. We thank the captains, crews, and science parties of the R/V Thompson, R/V Revelle, R/V Melville, R/V Kaiyo, R/V Shoyomaru, and the R/V Mirai. N. Bond and L. Rainville were supported by NSF Grant OCE-0827125. T. Farrar and S. Jayne were supported by NSF Grant OCE-0825152. B. Qiu was supported by NSF Grant OCN-0220680. The SST, wind stress, and SSH products were all accessed through the Asia-Pacific Data Research Center (APDRC). This is PMEL publication \#3706.

\section{Appendix 1. Error analysis for diffusivity estimate}

The temperature change due to diffusion is estimated as the residual of the mixed layer temperature budget Eq. (2) and diffusivity $(\kappa)$ is then estimated from this residual. The residual, however, contains the accumulation of all errors in the analysis. We make no attempt to quantify the errors due to unresolved processes, such as stratified shear flow convergence and vertical motions associated with mesoscale processes. As described in Section 4.2 we believe these unresolved processes can be large when the measured advection is large and therefore only attempt to interpret the residual of Eq. (2) in terms of diffusion when the estimated advection is relatively weak.

To estimate the propagation of errors in $\kappa$ due to errors in the various inputs to the calculation (e.g. surface heat flux, MLD, temperature measurements...), the derivative with respect to each input variable is estimated and multiplied by the error estimate in the variable. We assume that most errors can be reduced by averaging with the 5-day triangular filter, with the exception of the heat flux biases, and errors in the temperature gradient and vertical velocity. These are treated as biases. We assume that each source of error is independent; the net error is estimated by summing the square of each component and taking the square root. In general, our methodology follows that of Farrar (2007) with the exception of the error in advection. He assumes that the velocity and temperature gradient errors are not independent of each other. As an example of how the sources of errors can propagate through the calculations, we show the expression for the error in diffusivity due to an error in the MLD:

$$
\begin{aligned}
\frac{\partial \kappa}{\partial h} \operatorname{er}(h)= & \frac{1}{T_{z}}\left(\frac{\left.\lambda Q_{p e n}\right|_{-h}}{\rho C_{p}}-\frac{\partial T_{a}}{\partial t}-u_{a} \cdot \nabla T_{a}-\left(w_{-h}+\frac{\partial h}{\partial t}\right)\left(\frac{\partial T_{a}}{\partial h}-\frac{\partial T_{-h}}{\partial h}\right)\right. \\
& \left.-h \frac{\partial}{\partial h}\left(\frac{\partial T_{a}}{\partial t}-u_{a} \cdot \nabla T_{a}\right)\right) \operatorname{er}(h)
\end{aligned}
$$

Table A

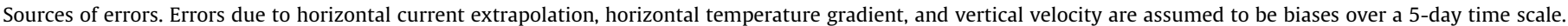

\begin{tabular}{|c|c|c|c|}
\hline Source of error & Error value & Rank 2004-2005 & Rank 2007-2009 \\
\hline Hourly surface turbulent heat flux & $\begin{array}{l}\text { Random: } 16 \mathrm{~W} / \mathrm{m}^{2}+10 \% \\
\text { Bias: }-5.7 \mathrm{~W} / \mathrm{m}^{2}\end{array}$ & 5 & 5 \\
\hline Radiative heat fluxes & $1 \%$ & & \\
\hline Mixed layer depth & (vertical spacing of temperature sensors spanning $h$ )/4 & 2 & 3 \\
\hline ATLAS and Seabird temperature sensors & $0.02{ }^{\circ} \mathrm{C}, 0.004{ }^{\circ} \mathrm{C}$ & 4 & 4 \\
\hline Current meter and ADCP velocity errors & $0.05 \mathrm{~m} / \mathrm{s}$ & 3 & 2 \\
\hline $\begin{array}{l}\text { Current extrapolation within } \\
\text { mixed layer below } 15 \mathrm{~m}\end{array}$ & $1.5 \times 10^{-3} \mathrm{~s}^{-1} \times$ depth, or $0.05 \mathrm{~ms}^{-1}$ whichever is largest & & \\
\hline Vertical velocity & $15 \%$ & 6 & 6 \\
\hline Horizontal $\nabla T_{a}$ & $2 \times 10^{-6} \mathrm{C} / \mathrm{m}$ prior to 1 April 2006; $1 \times 10^{-6}{ }^{\circ} \mathrm{C} / \mathrm{m}$ after 1 April 2006 & 1 & 1 \\
\hline
\end{tabular}
The errors are ranked in terms of their mean value for 2004-2005 and 2007-2009. A rank of 1 indicates this is the largest source of error in the diffusivity estimate. 
Sources of errors are summarized in Table A. Random and bias errors in the radiative and turbulent surface heat flux due to measurement errors were determined by Kubota et al. (2008). In addition we include a random $10 \%$ error in the turbulent flux bulk algorithm based on the Fairall et al. (2003) estimate for high winds. This is their high estimate. For low winds, they found errors reduced to $5 \%$. Errors in the MLD are estimated as the depth difference between sensors spanning the MLD multiplied by a factor of 0.25 . If the $0.2{ }^{\circ} \mathrm{C}$ temperature change at the base of the mixed layer occurred over an infinitely thin layer (i.e., as a step), the factor value would be 0.5 , while if the change occurred within a linear stratification between the two sensors, the factor would be very small and the error in MLD would be near zero. The 0.25 value thus appears to be a reasonable compromise. Errors in the sensor measurements are based upon the manufacturer's specifications. The velocity extrapolation error was estimated by scaling the root-mean-square of the upper ocean shear, observed by the ADCP mooring during the first 2 years, by the increased surface current magnitudes observed during later years. The error estimate in the vertical velocity was difficult to determine and thus is considered arbitrary. The error in the temperature gradient was estimated by first estimating the error at a single gridpoint through comparison with KEO, and then by computing the SST correlation between gridpoints used in the central finite difference.

As shown in Table A, the horizontal temperature gradient produces the largest error in $\kappa$. During 2004-2005, errors in $h$ were the second highest and errors in the mixed layer velocity were third. During 2007-2009 when the mooring had more subsurface sensors and the KE system had more eddies, this order was reversed. Throughout the record, the bottom three sources of errors were the subsurface temperature sensor measurement errors, net surface heat flux, and large-scale vertical velocity estimate.

\section{References}

Alexander, M., Deser, C., 1995. A mechanism for the recurrence of midlatitude SST anomalies during winter. J. Phys. Oceanogr. 25, 122-137.

Bond, N.A., Cronin, M.F., 2008. Regional weather patterns during anomalous airsea fluxes at the Kuroshio Extension Observatory (KEO). J. Climate 21, 1680-1697, http://dx.doi.org/10.1175/2007JCLI1797.1.

Bond, N.A., Cronin, M.F., Garvert, M., 2010. Atmospheric sensitivity to SST near the Kuroshio Extension during the extratropical transition of Typhoon Tokage. Mon. Weather Rev. 138, 2644-2663.

Bond, N.A., Cronin, M.F., Sabine, C., Kawai, Y., Ichikawa, H., Freitag, P., Ronnholm, K., 2011. Upper-ocean response to tyhpoon Choi-Wan as measured by the Kuroshio Extension Observatory (KEO) mooring. J. Geophys. Res. 116 (C02031), 8, http://dx.doi.org/10.1029/2010JC006548.

Cronin, M.F., Fairall, C.W., McPhaden, M.J., 2006. An assessment of buoy-derived and numerical weather prediction surface heat fluxes in the tropical Pacific. J. Geophys. Res. 111, C06038, http://dx.doi.org/10.1029/2005JC003324.

Cronin, M.F., McPhaden, M.J., 1997. Upper ocean heat balance in the western equatorial Pacific warm pool during September-December 1992. J. Geophys. Res. 102, 8533-8553.

Cronin, M.F., Meinig, C., Sabine, C.L., Ichikawa, H., Tomita, H., 2008. Surface mooring network in the Kuroshio Extension. IEEE Syst. Spec. Issue GEOSS 2 (3), 424-430.

D'Asaro, E.A., 1985. The energy flux from wind to near-inertial motions in the surface mixed layer. J. Phys. Oceanogr. 15, 1043-1059.

de Boyer Montégut, C., Madec, G., Fischer, A.S., Lazar, A., Iudicone, D., 2004. Mixed layer depth over the global ocean: an examination of profile data and a profilebased climatology. J. Geophys. Res. 109, C12003, http://dx.doi.org/10.1029/ 2004JC002378.

Donohue, K.A., Watts, D.R., Tracey, K., Wimbush, M., Park, J.-H., Bond, N., Cronin, M., Chen, S., Qiu, B., Hacker, P., Hogg, N.B., Jayne, S.R., McClean, J., Rainville, L., Mitsudera, H., Tanimoto, Y., Xie, S.-P., 2008. Program studies the Kuroshio Extension. EOS Trans. AGU 89 (17), 161-162.

Fairall, C.F., Bradley, E.F., Hare, J.E., Grachev, A.A., Edson, J.B., 2003. Bulk parameterization of air-sea fluxes: updates and verification for the COARE algorithm. J. Climate 16, 571-591.

Farrar, J.T., 2007. Air-Sea Interaction at Contrasting Sites in the Eastern Tropical Pacific: Mesoscale Variability and Atmospheric Convection at $10^{\circ} \mathrm{N}$. Ph.D. Thesis. Massachusetts Institute of Technology and the Woods Hole Oceanographic Institution, Cambridge, MA.

Gargett, A.E., Holloway, G., 1984. Dissipation and diffusion by internal wave breaking. J. Mar. Res. 42, 15-27.

Gregg, M.C., 1989. Scaling turbulent dissipation in the thermocline. J. Geophys. Res. 94, 9686-9698.
Gregg, M.C., Sanford, T.B., 1988. The dependence of turbulent dissipation on stratification in a diffusively stable thermocline. J. Geophys. Res. 93, 12,381-12,392.

Hanawa, K., Talley, L.D., 2001. Mode waters. In: Church, J., et al. (Eds.), Ocean Circulation and Climate. Academic Press, London, pp. 373-386.

Kako, S., Kubota, M., 2007. Variability of mixed layer depth in Kuroshio/Oyashio Extension region: 2005-2006. Geophys. Res. Lett. 34, L11612, http://dx.doi.or g/10.1029/2007GL030362.

Kelly, K.A., Dong, S., 2004. The relationship of western boundary current heat transport and storage to mid-latitude ocean-atmosphere interaction. In: Earth's Climate: The Ocean-Atmosphere Interaction. Am. Geophys. Un. Geophys. Monogr., 147, 347-363.

Konda, M., Ichikawa, H., Tomita, H., Cronin, M.F., 2010. Surface heat flux variations across the Kuroshio Extension as observed by surface flux buoys. J. Climate 23, 5206-5221.

Kubota, M., Iwabe, N., Cronin, M.F., Tomita, H., 2008. Surface heat fluxes from the NCEP/NCAR and NCEP/DOE reanalyses at the KEO buoy site. J. Geophys. Res. 113, C02009, http://dx.doi.org/10.1020/2007JC004338.

Minobe, S., Kuwano, A., Komori, N., Xie, S.-P., Small, R.J., 2008. Influence of the Gulf Stream on the troposphere. Nature 452, 206-209.

Mahadevan, A., Tandon, A., Ferrari, R., 2010. Rapid changes in mixed layer stratification driven by submesoscale instabilities and winds. J. Geophys. Res. 115, C03017, http://dx.doi.org/10.1029/2008JC005203.

Mori, K., Uehara, K., Kameda, T., Kakehi, S., 2008. Direct measurements of dissipation rate of turbulent kinetic energy of North Pacific subtropical mode water. Geophys. Res. Lett. 35, L05601, http://dx.doi.org/10.1029/2007GL032867.

Morozov, E.G., Velarde, M.G., 2008. Inertial oscillations as deep ocean response to hurricanes. J. Oceanogr. 64, 495-509.

Nonaka, M., Xie, S.-P., 2003. Covariations of sea surface temperature and wind over the Kuroshio and its extension: Evidence for ocean-to-atmosphere feedback J. Climate 16, 1404-1413.

Oka, E., Qiu, B., 2012. Progress of North Pacific mode water research in the past decade. J. Oceanogr 68, 5-20, http://dx.doi.org/10.1007/s10872-011-0032-5.

Oka, E., Suga, T., 2003. Formation region of North Pacific subtropical mode water in the late winter of 2003. Geophys. Res. Lett. 30, 2205, http://dx.doi.org/ 10.1029/2003GL018581.

Oka, E., Talley, L.D., Suga, T., 2007. Temporal variability of winter mixed layer in the mid- to high-latitude North Pacific. J. Oceanogr. 63, 293-307.

Park, J.-H., Donohue, K.A., Watts, D.R., Rainville, L., 2010. Distribution of deep nearinertial waves observed in the Kuroshio Extension. J. Oceanogr. 66, 709-717.

Paulson, C.A., Simpson, J.J., 1977. Irradiance measurements in the upper ocean. J. Phys. Oceanogr. 7, 952-956.

Price, J.F., 1983. Internal wave wake of a moving storm. Part I: scales, energy budget and observations. J. Phys. Oceanogr. 13, 949-965.

Price, J., Weller, R., Pinkel, R., 1986. Diurnal cycling: observations and models of upper ocean response to diurnal heating, cooling and wind mixing. J. Geophys. Res. 91, 8411-8427.

Qiu, B., 2002. The Kuroshio Extension System: its large-scale variability and role in midlatitude ocean-atmosphere interaction. J. Oceanogr 58, 57-75.

Qiu, B., Chen, S., 2006. Decadal variability in the formation of the North Pacific subtropical mode water: oceanic versus atmospheric control. J. Phys. Oceanogr 36, 1365-1380.

Qiu, B., Hacker, P., Chen, S., Donohue, K.A., Watts, D.R., Mitsudera, H., Hogg, N.G. Jayne, S.R., 2006. Observations of the Subtropical Mode Water evolution from the Kuroshio Extension System Study. J. Phys. Oceanogr. 36, 457-473.

Qiu, B., Kelly, K.A., 1993. Upper-ocean heat balance in the Kuroshio Extension region. J. Phys. Oceanogr. 23, 2027-2041.

Qiu, B., Schneider, N., Chen, S., 2007. Coupled decadal variability in the North Pacific: An observationally constrained idealized model. J. Climate 20, 3602-3620.

Reynolds, R.W., Smith, T.M., Liu, C., Chelton, D.B., Casey, K.S., Schlax, M.G., 2007. Daily high-resolution blended analyses for sea surface temperature. J. Climate 20, 5473-5496.

Stark, J.D., Donlon, C.J., Martin, M.J., McCulloch, M.E., 2007. OSTIA: An operational, high resolution, real time, global sea surface temperature analysis system. In: Proceedings of the Oceans '07 IEEE Aberdeen Conference. Marine Challenges: Coastline to Deep Sea. Aberdeen, Scotland. IEEE.

Sukigara, C. Suga, T., Saino, T., Toyama, K., Yanagimoto, D., Hanawa, K., Shikama, N., 2011. Biogeochemical evidence of large diapycnal diffusivity associated with the Subtropical Mode Water of the North Pacific. J. Oceanogr. 67, 77-85, http://dx.doi.org/10.1007/s10872-011-0008-5.

Taguchi, B., Nakamura, H., Nonaka, M., Xie, S.-P., 2009. Influences of the Kuroshio/ Oyashio Extensions on air-sea heat exchanges and storm track activity as revealed in regional atmospheric model simulations for the 2003/4 cold season. J. Climate 22, 6536-6560.

Tokinaga, H., Tanimoto, Y., Xie, S.-P., Sampe, T., Tomita., H., Ichikawa, H., 2009. Ocean frontal effects on the vertical development of clouds over the western North Pacific: in situ and satellite observations. J. Climate 22, 4241-4260.

Teague, W.J., Carron, M.J., Hogan, P.J., 1990. A comparison between the Generalized Digital Environmental Model and Levitus climatologies. J. Geophys. Res. 95, 7167-7183.

Tomita, H., Kako, S., Cronin, M.F., Kubota, M., 2010. Preconditioning of the wintertime mixed layer at the Kuroshio Extension Observatory. J. Geophys. Res. 115, C12053, http://dx.doi.org/10.1029/2010JC006373.

Vivier, F., Kelly, K.A., Thompson, L., 2002. Heat budget in the Kuroshio Extension region: 1993-99. J. Phys. Oceanogr. 32, 3436-3454.

Yasuda, I., Tozuka, T., Noto, M., Kouketsu, S., 2000. Heat balance and regime shifts of the mixed layer in the Kuroshio Extension. Prog. Oceanogr. 47, 257-278. 